\title{
Ontology Model and Application for the CNC Integrated Detection
}

\author{
Libing Liu Weidong Yang Zeqing Yang \\ School of Mechanical Engineering, Hebei University of Technology, Tianjing 300130, P.R. China
}

\begin{abstract}
CNC integrated inspection is an important component for monitor and diagnosis in integrated manufacturing process, and is a pivotal step avoiding grave incidents timely and effectively. Combined with the methods used before in the CNC integrated inspecting plan, an improved domain ontology knowledge model which used in the CNC integrated inspection has been proposed. The simulations show that the method is normative and practical. The applications of the ontological theory in CNC integrated manufacturing can not only provide better platform for information and the knowledge integration, but also can make the contribution to helping the popularization and deepening ontological theory.
\end{abstract}

Keywords: Domain ontology, Knowledge express, Application model, Integrated inspection, CNC (Computer numercal control)

\section{Introduction}

Ontology is referred to the origin and nature of the things stemmed from the philosophy concept. Ontology is introduced by the field of artificial intelligence then, and to explicit specification of a conceptualization. Ontology can explicitly express all kinds of concepts and interrelationships in the field, so it plays an important role in the semantics. Since the ontology adopts precise formal language, precise syntax and clear semantics, the relationships between concepts, concept and object, objects in the problem domain become clearer, which significantly reduces the possible misunderstanding of the concept and logic relation in the problems. The Ontology thinking and its research methods will be used to the CNC integrated detection knowledge field in this paper, which achieve the intelligent planning of the CNC integrated detection and make up for the shortcomings of traditional methods[1]-[3].

At present, advanced manufacturing technology is developed from digital manufacturing to integrated manufacturing, intelligent manufacturing and information manufacturing. The use of the CNC
Integrated Detection Technology is becoming more and more widespread. The CNC technology has transmitted from the digital stage that as the center of the computer information processing technology including numerical calculation and data processing into the new integrated and intelligent stage that as the center of the knowledge processing, and the knowledge processing technology will become one of the core technology in the knowledge society Information Integration [14] [15].

\section{Knowledge processing methods}

The method of the knowledge processing is the method that the human knowledge carries on expression, classification, acquisition, learning, and expand through the computer technology. Table 1 indicates the common methods and features of knowledge expression.

We can see the object-oriented knowledge representation method, process mode method; predicate logic method, production rule method exits the shortcomings to varying degrees, and can not accurately describe a large number of technological knowledge involved in the CNC integrated detection.

Ontology is an advanced knowledge representation technique in the field of the artificial intelligence. It reflects the abstract nature of the things or the phenomenon by the relationship between the concepts, and accurately understands the relationship between things. Therefore, the ontology can be used to describe the link between the concepts in a certain field or even within the broader scope. The knowledge is only described using the precise and formal language through establishing the abstract model, which make these concepts and links have clear definition in a certain scope and can achieve the manmachine communication consensus[5][6].

Therefore, CNC Integrated Detection knowledge is described by the ontology thinking in the paper, which can meet the needs of the knowledge sharing and knowledge exchange in the CNC Integrated Detection. Therefore, this paper proposes the description on the use of ontological theory on CNC 
integrated detection knowledge, and suggests that the field application pattern specifically for the integrated detecting of CNC, try to be able to satisfy the need of the knowledge sharing and exchanging in CNC integrated inspection[7][8].

\begin{tabular}{|c|c|c|}
\hline $\begin{array}{l}\text { Method } \\
\text { names }\end{array}$ & Description & Method Features \\
\hline $\begin{array}{l}\text { Object- } \\
\text { oriented } \\
\text { knowledg } \\
\text {-e } \\
\text { represent } \\
\text { ation } \\
\text { method }\end{array}$ & $\begin{array}{l}\text { Express } \\
\text { knowledge as } \\
\text { various objects, } \\
\text { the complex } \\
\text { knowledge can be } \\
\text { composed of the } \\
\text { several objects. }\end{array}$ & $\begin{array}{l}\text { The method is not } \\
\text { mature, and is also in } \\
\text { the further studies. }\end{array}$ \\
\hline $\begin{array}{l}\text { Process } \\
\text { mode } \\
\text { method }\end{array}$ & $\begin{array}{l}\text { Knowledge is } \\
\text { included in the } \\
\text { process, and the } \\
\text { process describes } \\
\text { the relationship } \\
\text { between the things } \\
\text { and the practical } \\
\text { work. }\end{array}$ & $\begin{array}{l}\text { The achieved results } \\
\text { are incomplete, } \\
\text { inconsistent and of high } \\
\text { maintenance costs. }\end{array}$ \\
\hline $\begin{array}{l}\text { Predicate } \\
\text { Logic } \\
\text { method }\end{array}$ & $\begin{array}{l}\text { Express the } \\
\text { subject and object } \\
\text { in the form of the } \\
\text { predicate, and } \\
\text { describe the } \\
\text { resources. }\end{array}$ & $\begin{array}{l}\text { Although it has strong } \\
\text { logic reason, we can } \\
\text { only reason on the level } \\
\text { of grammar, and can't } \\
\text { get the semantic } \\
\text { understanding to the } \\
\text { described resources. }\end{array}$ \\
\hline $\begin{array}{l}\text { Producti- } \\
\text { on rule } \\
\text { method }\end{array}$ & $\begin{array}{l}\text { If the precondition } \\
\text { is satisfied, then } \\
\text { complete the } \\
\text { following action. }\end{array}$ & $\begin{array}{l}\text { In the fuzzy matching, } \\
\text { when the number of the } \\
\text { production rule is very } \\
\text { large, the matching time } \\
\text { is very long and not } \\
\text { suitable for large-scale } \\
\text { knowledge } \\
\text { reasoning. }\end{array}$ \\
\hline $\begin{array}{l}\text { Frame } \\
\text { work } \\
\text { Descripti } \\
\text {-on } \\
\text { method }\end{array}$ & $\begin{array}{l}\text { Express the } \\
\text { knowledge in the } \\
\text { form of data } \\
\text { structure. }\end{array}$ & $\begin{array}{l}\text { Not good at expressing } \\
\text { process knowledge, the } \\
\text { description of complex } \\
\text { information is too } \\
\text { complicated and not } \\
\text { conducive to computer } \\
\text { automation process. }\end{array}$ \\
\hline $\begin{array}{l}\text { Ontology } \\
\text { Descripti } \\
\text {-on } \\
\text { method }\end{array}$ & $\begin{array}{l}\text { The resources are } \\
\text { unambiguously } \\
\text { described using } \\
\text { the precise and } \\
\text { formal language } \\
\text { according to the } \\
\text { nature relations } \\
\text { between internal } \\
\text { matters. }\end{array}$ & $\begin{array}{l}\text { It can be } \\
\text { unambiguously } \\
\text { described } \\
\text { knowledge, and it is a } \\
\text { new study direction in } \\
\text { the field of knowledge } \\
\text { engineering, which } \\
\text { have a larger study and } \\
\text { practical value. }\end{array}$ \\
\hline
\end{tabular}

Table 1: Methods of knowledge expression

\section{Domain Ontology construction}

Establishing the domain ontology model is a complex system engineering, which needs the participation of many experts and technologists and the massive time. To a certain degree, establishing the domain ontology model is a new kind of software activity, there are two cores in the project thought that are the standardized expression ways and standardized steps. Compared with common software, the ontology emphasized sharing and reusability, it provides the unified semantic integration between the different systems. Therefore, its project nature is more obvious. compared with the traditional software development, establishing the ontology model should emphasize the evolution, and instruct evolution process through methodology; Next, it should reduce the participation of the domain experts and the degree of the Ontology establishing, which makes the establish process easy to operate, we should attach importance to this problem in the methodology, but it is not solved very well in existing methodology [9]-[11].

\subsection{Ontology elements}

Establish the Ontology knowledge model includes classes or concepts, relations, functions, axioms and instances. There are four kinds of the basic relationship in the semantic sense as shown in Table 2.

\begin{tabular}{|l|l|}
\hline $\begin{array}{l}\text { Relations } \\
\text { names }\end{array}$ & Relations description \\
\hline part-of & $\begin{array}{l}\text { Express the relationship between parts } \\
\text { and whole of the concepts }\end{array}$ \\
\hline kind-of & $\begin{array}{l}\text { Express the succession relations of the } \\
\text { concepts, similar to the relationship } \\
\text { between Father class and subclass in the } \\
\text { object-oriented. }\end{array}$ \\
\hline instance-of & $\begin{array}{l}\text { Express the relationship between the } \\
\text { concept instance and the concepts, similar } \\
\text { to the relationship between objects and } \\
\text { classes in the object-oriented. }\end{array}$ \\
\hline $\begin{array}{l}\text { attribute- } \\
\text { of }\end{array}$ & $\begin{array}{l}\text { Express a certain concept is the attribute } \\
\text { of another concept. For example, the } \\
\text { "price" is the attribute of the table. }\end{array}$ \\
\hline
\end{tabular}

Table 2: Basic relationships of ontology elements

\begin{tabular}{|l|l|}
\hline $\begin{array}{l}\text { Relations } \\
\text { names }\end{array}$ & Relations description \\
\hline $\begin{array}{l}\text { constraint- } \\
\text { of }\end{array}$ & $\begin{array}{l}\text { Expressing the constraint } \\
\text { Relationship among the concepts, for } \\
\text { example, the constraint conditions } \\
\text { between inspecting route and working } \\
\text { axis. }\end{array}$ \\
\hline $\begin{array}{l}\text { feedback - } \\
\text { of }\end{array}$ & $\begin{array}{l}\text { Expressing the feedback relationship } \\
\text { among the concepts, for example, the } \\
\text { sampled numbers could be reduced and } \\
\text { image information should be compressed } \\
\text { for the less influenced sector. }\end{array}$ \\
\hline $\begin{array}{l}\text { equality- } \\
\text { of }\end{array}$ & $\begin{array}{l}\text { Expressing the equality relationship } \\
\text { among the concepts, for example, } \\
\text { working movement codes and inspecting } \\
\text { movement codes, etc }\end{array}$ \\
\hline
\end{tabular}

Table 3: Expansion of relations of ontologv elements 
In practical modeling process, the relationship between the concepts is not limited to the above listing; according to the specific circumstances of the domain define the corresponding relationship. Based on the application situation, we have defined relevant extended relationships in Table 3. There are large amount of the objects constraint in integrated inspecting of CNC, for example, the direction of a working part is constrained; the dimension of multiaxis is constrained, and so on. Therefore, we should define the constraint relations and its attribute between the concepts. Constantly optimizing and innovations of related domain ontology knowledge are depended on the feedbacks based on the inspecting process. So, we should define the feedback relations and its mapping character. If it is belonged to the embedded CNC integrated inspecting, we should adopt some concepts of the original system, then define the equality relationship character [4] [12] [13].

\subsection{Domain ontology knowledge model}

Domain knowledge representation is the key of knowledge processing, the premise of knowledge acquisition and the base of knowledge utilization. The scientific normalized domain knowledge representation is the foundation of building domainspecific ontology. Obviously, the key of realizing CNC integrated detection is intelligent planning process based on knowledge reasoning. Therefore, all kinds of knowledge in the whole work cycle and detection planning process of CNC integrated system is the domain-specific knowledge. The important research of domain-specific knowledge representation is to use what kind of method to solve knowledge needed by the domain problems. The knowledge is stored in computer and easy to be handled by computer. The success or failure of the knowledge system is directly determined by whether the representation of domain-specific knowledge is appropriate.

The CNC domain knowledge of integrated detection involves very broadly, including detecting condition, detecting plan, detecting control, detecting processing and so on. Therefore, domain ontology knowledge systems can be constructed by using different methods. Figure 1 shows the top-based construction. Obviously, all kind of the related domain ontology knowledge including CNC control devices, machine tools, measuring devices, scanning, data processing, communication devices are integrated in this system. The study show that the basic classes of knowledge ontology on CNC integrated detection include CNC control system, machine tool,

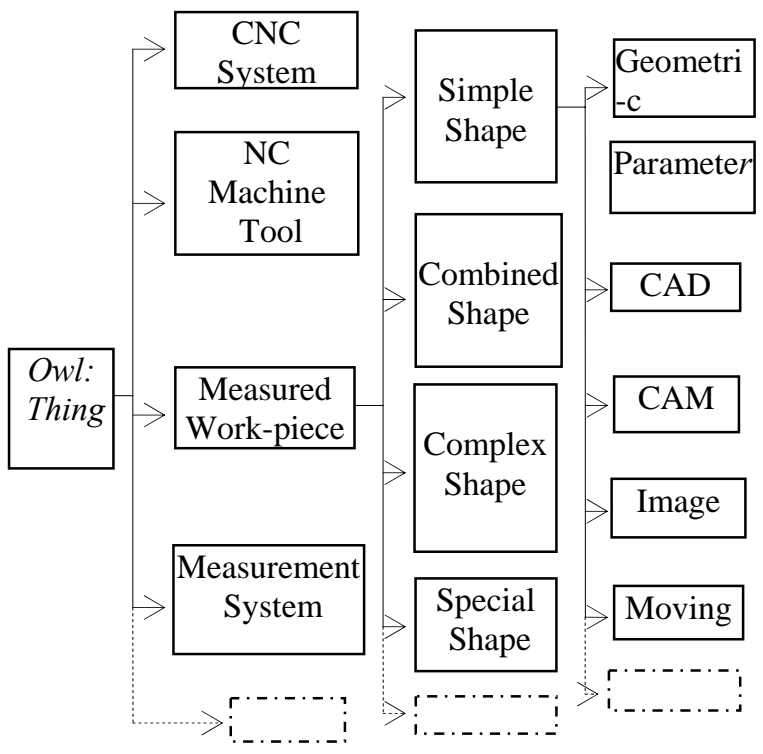

Fig.1: Basic type of the domain ontology

measurement system, measured work-piece, detection condition and so on. Multi-layer hierarchical relations are shown in Figure1.Owl: Thing is defined as father class of all classes. In the domain knowledge-the class of measured work-piece, the related information is classified to the subclasses such as simple shape, combined shape and surface, special shape and surface etc. according to geometry knowledge. The other subclasses such as the subclass of simple shape and surface are shown in Figure 2. Each of classes has a number of subclasses. For example, the subclass of simple shape has its subclasses such as geometric model, parameter model, CAD model, CAM model,

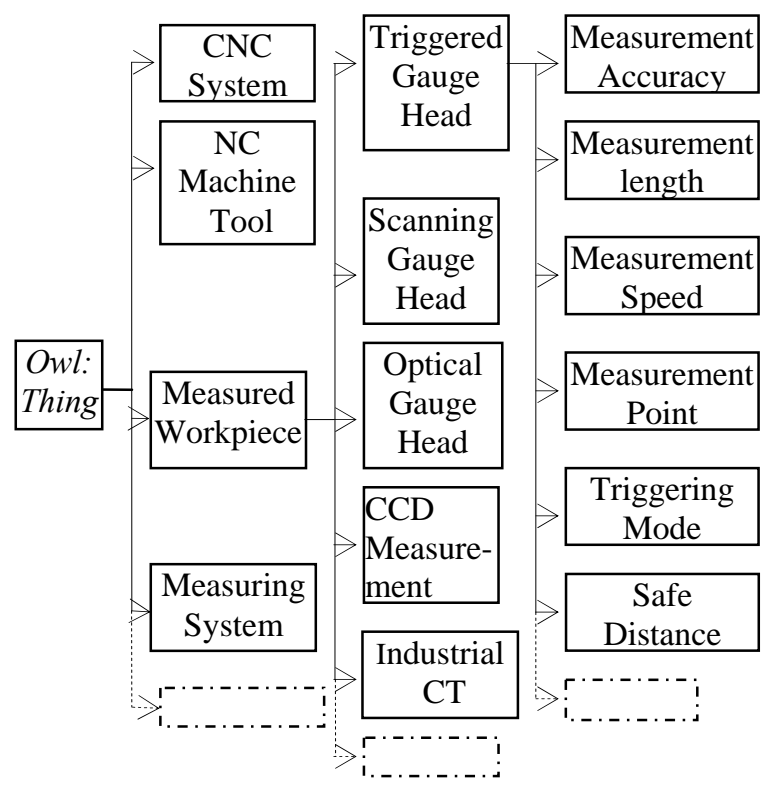

Fig.2: Schematic of foliation classes model 
image model and moving object model and so on.

The subclass of measurement system-triggered gauge head is shown in Figure 2.The measurement system include the subclasses such as triggered gauge head, scanning gauge head, optical gauge head, CCD measurement and industrial CT and so on. The relation of triggered gauge head class and its subclasses include the subclasses such as measurement condition, measurement accuracy, and measurement methods and so on. The subclass of triggered method includes its subclasses such as one-contact detection and twocontact detection and so on.

Research shows that the fundamental essences of CNC integrated knowledge system includes requirement essence, environment essence, concept essence, method essence, rule essence, model essence, data essence, control essence, analyze essence, explain essence, translate essence and so on. In fact, the interactions among domain essences are very complex. Thereby we put forward a redundancy node-based model by taking the advantage of the methods that has been used and improve the constructing method:Choose the class from the top-based model to be the fundamental construction of field model; Choose the interacting pattern from the middle-based model to form; Based on the interactions among the knowledge elements of the bottom model, the redundant sub nodes shapes; Based on the construction of require essences of the out ring, a entire domain ontological has been improved.

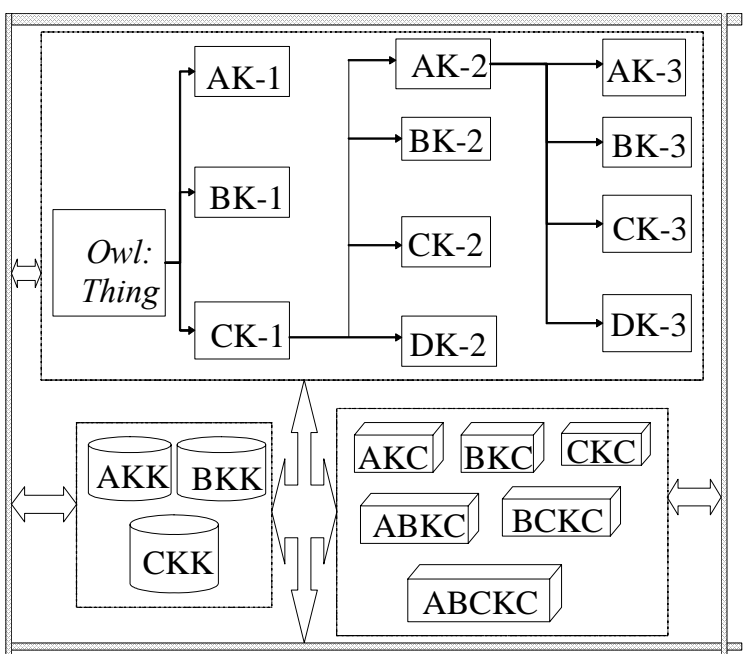

Fig.4: Nodes-based model

The improved ontology structure may be shown in Figure 3. Therefore, in accordance with the basic structure is divided into three categories, the first layer of the system ontological category knowledge, The second tier category ontological knowledge reasoning, explained the third tier category ontology knowledge;
The interactions between the classes may be identified

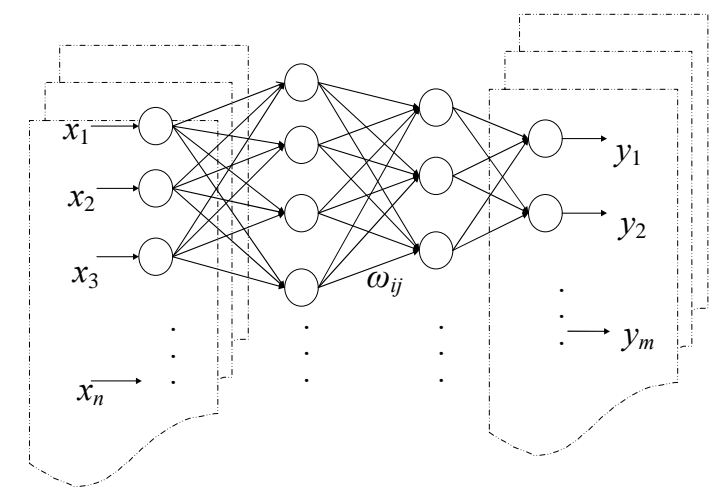

Fig.5: Relation model between nodes

through the substructures signed $\mathrm{KK}$, and the interaction between the elements could also be identified through the sub-nodes $\mathrm{KC}$, which consist of the redundancy ontology knowledge node. It shows in the map, that AK-1 is the first category of system knowledge ontology, BK-1 the second category system ontology; AK-2 is the first category of reasoning ontology, and BK-2 the second category of reasoning ontology; AK-3 the first category explain ontology, BK-3 the third category explain ontology. We can see that in the improved system more complex reasoning could be solved by use of the sub-structure and sub-nodes, and the domain ontology model could be simplified model based on the redundant knowledge nodes. The relation model of the elements in KK and KC are show in Fig.4. The model of nodes based is

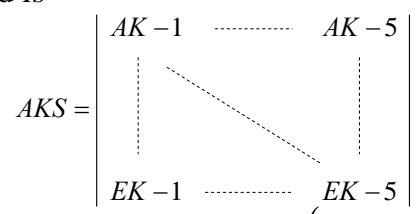

In Figure 4 , the input is $\left(\begin{array}{llll}x_{1} & x_{2} & \ldots . . & x_{n}\end{array}\right)$, the output is $\left(\begin{array}{llll}y_{1} & y_{2} & \ldots . . & y_{m}\end{array}\right)$. The right function is:

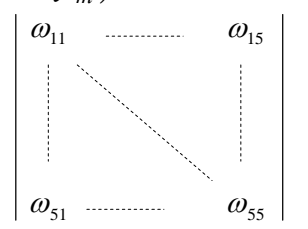

The classes are signed in $\mathrm{K}$; the actions between the classes are showed in $\mathrm{KK}$, and the actions between the nodes in KC.

\section{Knowledge reasoning}

\subsection{Intelligent reasoning algorithm}


Knowledge reasoning is the process of generating new knowledge according to fact sets and reasoning rules; there are two kinds: forward reasoning and backward reasoning. In the process of the backward reasoning, if there exits many available rules, and then easily lead to the recursive call deeply, which affect the performance of the whole reasoning algorithm, but the backward reasoning is indispensable to the real-time interaction between users. Therefore, the forward reasoning algorithm is adopted in the CNC integrated detection knowledge reasoning as shown in Figure 5.

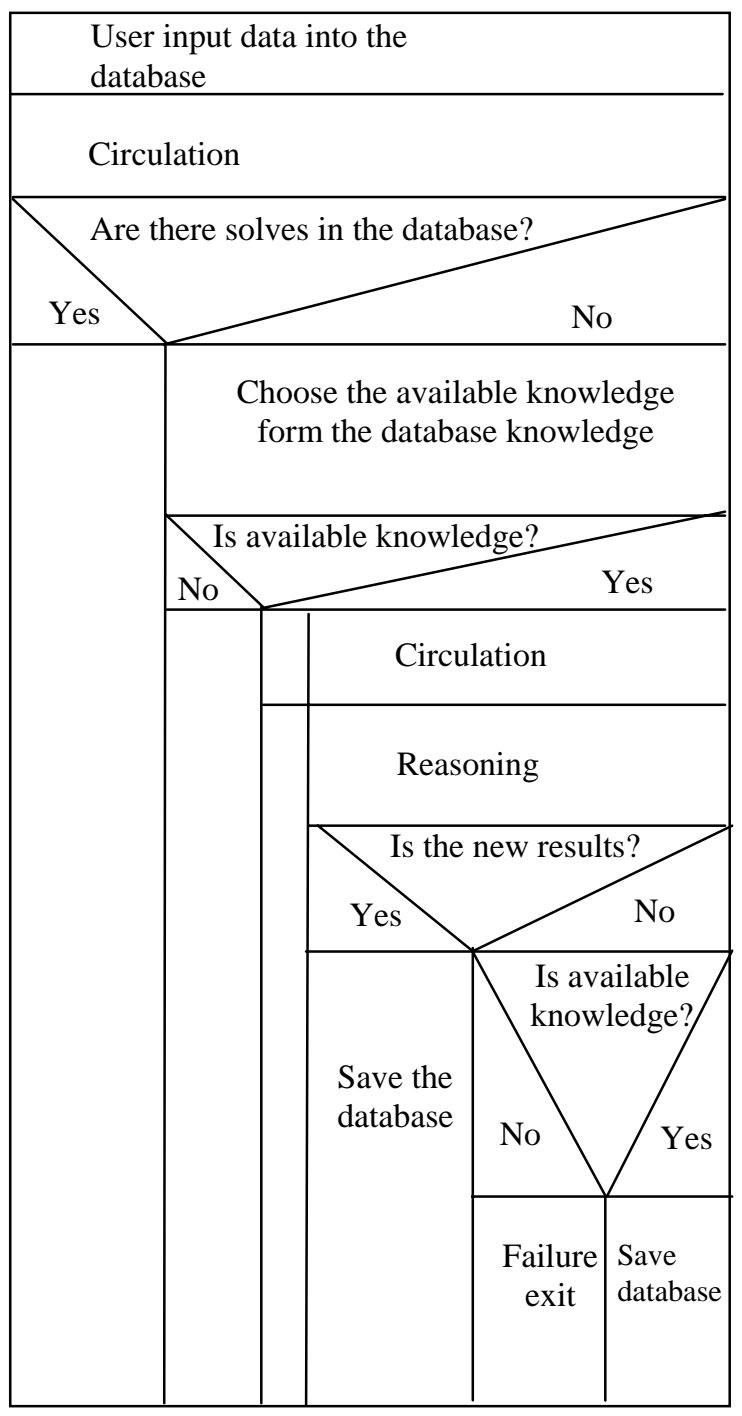

Fig.5: Schematic of forward reasoning process

\subsection{Application system}

The component of the CNC Integrated Detection System is shown in Figure 6. The unified semantics of knowledge can be described based on OWL through domain ontology knowledge model construction; the new knowledge can be acquired based on the database and integration of knowledge using forward reasoning algorithm. Basic inspection simulation results are listed in Figure 7.

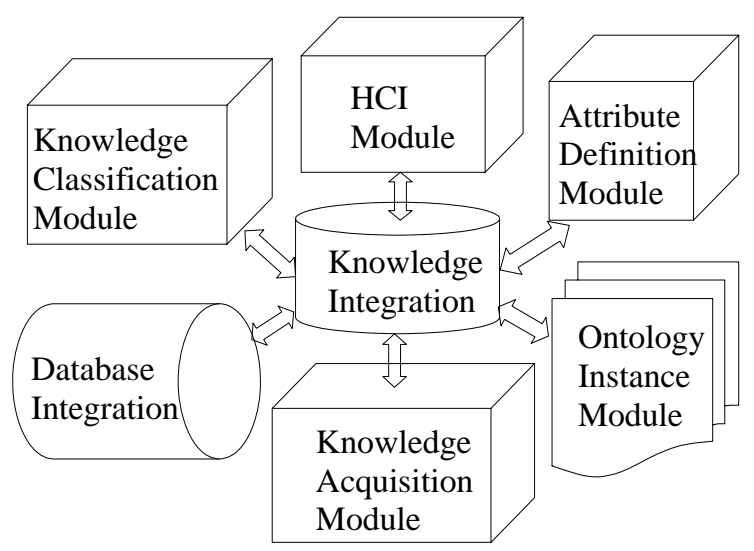

Fig.6: General system functions schematic

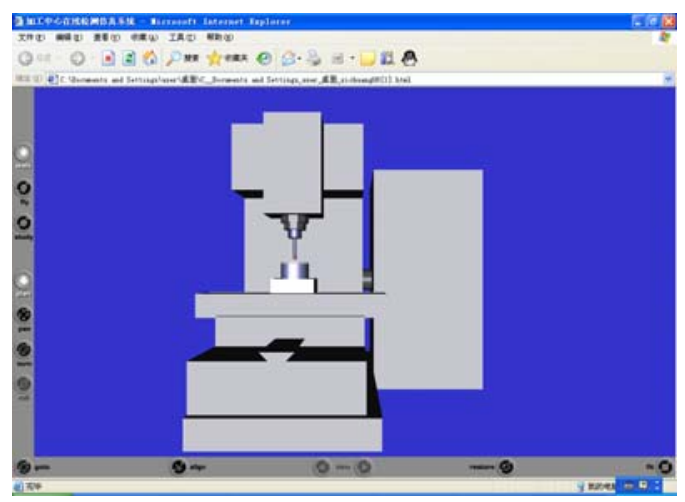

(a) Process simulation of $x$-inspection

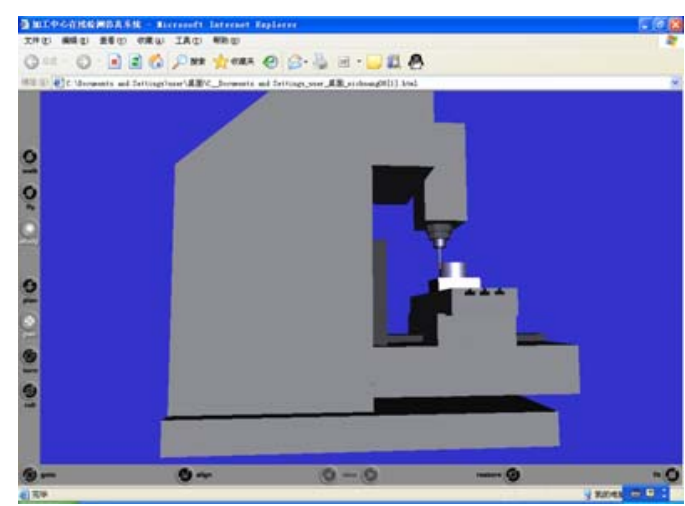

(b) Process simulation of y-inspection

Fig.7: CNC integrated detection simulation 


\section{Conclusions}

People is always accustomed to using Newtonian mechanics frame to resolve the system problem which is solved by dividing complicated system into the simple parts and this method is also used today. In fact, every part in the system which is mutual coupling should be considered as an integrated one for the solution of the complicated problem. Therefore, the integreted system problems are studied by the way which was put forward by Puligaojin. In ontologybased system the mechanics way has been combined with the Puligaojin frame, which has been used to build a CNC integrated detection system. It shows that this application could simplify the main frame of the integrated system and change its inner complex relations to the redundant node-base net. So its characteristics are given as follows:

1) The key problem about complicated system knowledge integration can be solved based on the knowledge shared and knowledge reusable technology. 2) Domain ontology knowledge model establishing is the groundwork of knowledge learning process based on intelligent reasoning.

3) The knowledge integration system is based on ontology academic, which provides normative and extensible intelligent planning flat roof for CNC integration detection.

4) Ontology-based Integrated Detection Technology practical application can be achieved, according to further thinning the domain knowledge and deepening the inference rules.

\section{References}

[1] K. A. Aldakhilallah, R. Ramesh, An integrated framework for automated process planning. Design and Analysis, pp: 939-956, 1998.

[2] Z. G. Yang, X. K. Wang, C. Y. Liu, Z. Q. Wei, Process knowledge representation based on information element and the corresponding inference mechanism. Journal of Dalian Railway Institute, 21:23-28, 2000.

[3] G.B. Zhang, S. L. Wang, Z. J. Xu, editor. Advanced manufacturing technology, The Press of Chongqing University, Chongqing, 1996.

[4] S. Zhang, editor. Dispersed network manufacturing, China Machine Press, Beijing, 1999.

[5] K.P. Sycara, Machine learning for intelligent support of conflict resolution. Decision Support Systems, pp: 121-136, 1993.

[6] Q. Fu, S. S. Zhang, J. M. Hu, Study on ontologybased domain knowledge sharing. Computer
Integrated Manufacturing Systems, pp. 54-58, 2001.

[7] H. Takeda, K. Iino, T. Nishida, Agent organization and communication with multiple ontologies. International Journal of Cooperative Information Systems, pp. 321-337, 1995.

[8] Y. L. Chen, editor. IDEF modeling analysis and design method, the press of Tsinghua Universty, Beijing, 2000.

[9] M. Genesereth, R. E. Fikes, Knowledge interchange format, version 3.0 reference manual. Technical Report Logic-92-1, Computer Science Department, Stand ford University, 1992.

[10] M. Genesereth, Knowledge interchange format. In Proceeding of the Second International Conference, pp. 599-600, 1991.

[11] Y.P. Hao and C. H. Wang, Study on knowledge sharing in the whole process of product based on ontology. Chinese Journal of Mechanical Engineering, 39:126-130, 2002.

[12] Y.S. Chen, L.B. Liu, M. L. Zhang, H. Rong, Study on Coordinated Control and Hardware System of a Mobile Manipulator. The 6th World Congress on Intelligent Control and Automation, pp.9037-9041, 2006.

[13] L.B. Liu, W.L. Liu, Y. S. Chen, Development of wireless dnvironmental monitoring system based on GPRS. Fouth International Conference in IT\& Application, pp. 113-117, 2007.

[14] L.B. Liu, H.Q. Sang, Y. S. Chen, Study on the new method of on-line inspecting for work-pieces in a machining Center. New Technology \& New Process, 11:16-18, 2005.

[15] L.B. Liu, H.Q. Sang, Y.S. Chen, On-line inspecting and controlling for workpieces with touch trigger probes. Manufacturing Technology \& Machine Tool, 12:25-27, 2006. 